$20 \begin{aligned} & \text { Pesquisa Florestal Brasileira } \\ & \text { Brazilian Journal of Forestry Research } \\ & \text { www.cnpf.embrapa.br/pfb }\end{aligned}$

\title{
Nota Científica \\ Distribuição de diâmetros de um cerradão distrófico no Distrito Federal (DF), Brasil
}

\author{
Juliana Silvestre Silva1, Jeanine Maria Felfili² \\ ${ }^{1}$ Universidade de Brasília, Instituto de Ciências Biológicas, Departamento de Botânica, Caixa Postal 4457, CEP 70910-970, Brasília, DF, Brasil \\ ${ }^{2}$ Universidade de Brasília, Faculdade de Tecnologia, Departamento de Engenharia Florestal, Brasília, DF, Brasil (in memoriam)
}

"Autor correspondente:

julissilva@unb.br

Termos para indexação:

Potencial regenerativo

Estrutura demográfica

Unidade de conservação

Index terms:

Regenerative potential

Demographic structure

Conservation area

\begin{abstract}
Resumo - Este estudo avaliou a estrutura diamétrica da reserva biológica do Cerradão (REBIO do Cerradão), a partir da análise das distribuições diamétricas da comunidade e das principais populações, determinadas pelo valor de importância (VI). A relação da distribuição dos indivíduos por classes de diâmetro foi avaliada por análises de regressão e variância. Os valores de " $\mathrm{q}$ " e " $\mathrm{R}$ " indicaram que Qualea grandiflora Mart. foi a espécie com distribuição mais balanceada e maior tendência ao equilíbrio, e Terminalia fagifolia Mart. a única que não apresentou curva do tipo J-invertido. O cerradão parece conseguir se restabelecer após eventos fortuitos, mas novas medições precisam ser feitas para a obtenção de conclusões mais contundentes.
\end{abstract}

Histórico do artigo: Recebido em 22/05/2012

Aprovado em 19/11/2012

Publicado em 28/12//2012

doi: $10.4336 / 2012 . p f b .32 .72 .463$

\section{Diametric distribution of a dystrophic cerradão in Distrito Federal, Brazil}

\begin{abstract}
This study evaluated the diametric structure of the biological reserve of Cerradão (REBIO do Cerradão), from the analysis of the diametric distributions of the community and its main populations, ordered according to the importance value (IV). The individuals distribution ratio by diametric classes were evaluated by regression and variance analysis. The values of " $\mathrm{q}$ " and " $\mathrm{R}$ " indicated that Qualea grandiflora Mart. was the species with the most balanced distribution and greater tendency to equilibrium, and Terminalia fagifolia Mart. the only one that did not show the J-reverse shape. The cerradão seems to be able to recover from random events, but new measurements need to be made to permit more robust conclusions.
\end{abstract}

Uma ótima ferramenta para obter dados sobre a estrutura de tamanho de populações ou crescimento dos indivíduos arbóreos nas regiões tropicais é a medição diamétrica dos troncos (Silva Júnior \& Silva, 1988). Este tipo de medição é também uma importante técnica na condução de planos de manejo para conservação, já que a análise da distribuição de diâmetros pode resgatar o passado (ocorrência de perturbações) e predizer o futuro das comunidades vegetais, fornecendo informações que auxiliam na tomada de decisões sobre uma possível necessidade de reposição florestal (Scolforo et al., 1998). Imaña-Encinas et al. (2007) afirmam que estudos fitossociológicos fornecem informações que permitem contribuir para o melhor conhecimento e conservação de remanescentes florestais, visto que retrata a distribuição e densidade das espécies (Santos et al., 2007). Um exemplo é a presença de espécies consideradas raras em determinado local e comuns em outros, o que pode ser reflexo de características como distribuição restrita ou agrupada, ou ainda exigências ambientais. 
O cerradão é uma das fitofisionomias mais vulneráveis do bioma Cerrado, pois é amplamente substituído pela agricultura, devido a sua topografia plana e solos profundos e aráveis, e usado para exploração madeireira, já que abriga espécies comuns a ambientes florestais, cujo diâmetro e altura são mais elevados (Felfili, 2001b). Ribeiro \& Walter (2008) classificam a fitofisionomia como uma formação florestal que compartilha espécies com o cerrado sensu stricto e florestas do bioma. De acordo com os autores, caracterizam-se pela fertilidade do solo que ocupam, sendo chamados distróficos os cerradões sobre solos pouco férteis e mesotróficos os cerradões sobre solos de fertilidade mediana. Em cerradões distróficos as espécies apresentam menor porte e cobertura de copa, ocasionando maior densidade de indivíduos, enquanto cerradões mesotróficos apresentam valores de área basal mais elevados e menor densidade por hectare, visto que a fertilidade destes solos favorece o crescimento dos indivíduos e a consequente diminuição no seu número (Araújo \& Haridasan, 1988). Por este motivo, alguns autores afirmam que os cerradões distróficos abrigam preferencialmente espécies savânicas, já que sua baixa fertilidade não propicia o estabelecimento de espécies de maior porte (Ribeiro \& Walter, 2008).

Segundo Souza et al. (2010), a transição de cerrado sensu stricto para cerradão não é rara e ocorre de maneira suave, com aumento em tamanho e densidade dos indivíduos arbóreos e diminuição do número de arbustos e herbáceas, até que se perceba a formação de um dossel. Haridasan (1992) afirma que a transição cerrado sensu stricto - cerradão pode ser resultante de fatores edáficos favoráveis como, por exemplo, a maior disponibilidade de água no solo. De acordo com o autor, essa transição também pode ser reflexo da maior disponibilidade de nutrientes no passado, que permitiu o aumento da biomassa das espécies estabelecidas nas áreas de cerradão. Essa vegetação continuaria a sobreviver sob as atuais condições do solo através da ciclagem fechada de nutrientes, o que explicaria a diferença na composição florística entre cerrado e cerradão, supondo que as espécies de cerradão eram mais competitivas na presença de maior quantidade de nutrientes. Segundo Haridasan (1992), isso parece possível, pois várias espécies de cerradão também ocorrem em ambientes florestais, onde os solos são mais férteis.

No Distrito Federal a maior mancha de cerradão distrófico está inserida na Reserva Biológica (REBIO) do Cerradão, Unidade de Conservação(UC) de Proteção Integral localizada na Área de Proteção Ambiental (APA) Gama e Cabeça de
Veado. A REBIO do Cerradão foi criada como Área de Relevante Interesse Ecológico (ARIE) e transformada em REBIO através dos Decretos $n^{\circ}$ 19.213/98 (Instituto Brasília Ambiental, 2010) e no 31.757/10 (Distrito Federal, 2010), respectivamente, devido às suas características ambientais e ecológicas, importantes para a conservação da fitofisionomia. Localiza-se sob as coordenadas $15^{\circ} 51^{\prime} \mathrm{S}$ e $47^{\circ} 49^{\prime} \mathrm{W}$ e ocupa uma área de 54,12 ha, abrigando 16 ha de cerradão e cerrado denso adjacente (Distrito Federal, 2006). O clima predominante da área, segundo Köppen, é Tropical deAltitude (Cwa), com temperatura no mês mais frio inferior a $18{ }^{\circ} \mathrm{C}$ e superior a $22^{\circ} \mathrm{C}$ no mês mais quente. Com índice pluviométrico entre $1.350 \mathrm{~mm}$ e $1.450 \mathrm{~mm}$, a REBIO é uma área considerada de extrema importância para o equilíbrio do regime hídrico do $\mathrm{DF}$, pois se encontra em uma região com potencial de recarga de aquífero em torno de $50 \%$ (Instituto Brasília Ambiental, 2010).

Segundo análise físico-química feita na área, o solo na UC é do tipo Latossolo Vermelho, com saturação por bases de $6 \%$ no cerradão e $8 \%$ no cerrado denso. Os valores de alumínio $(\mathrm{Al})$, magnésio $(\mathrm{Mg})$ e potássio $(\mathrm{K})$ são muito parecidos nas duas fitofisionomias $(\mathrm{Al}=$ 1,4 cmolc kg-1 e 1,1 cmolc kg-1; $\mathrm{Mg}=0,1 \mathrm{cmolc} \mathrm{kg}^{-1} \mathrm{e}$ 0,2 cmolc kg-1; $\mathrm{K}=50,7 \mathrm{mg} \mathrm{kg}^{-1}$ e $42,9 \mathrm{mg} \mathrm{kg}^{-1}$ para cerradão e cerrado denso, respectivamente), enquanto cálcio $(\mathrm{Ca})$ e sódio $(\mathrm{Na})$ apresentam quantidades iguais em ambos os solos $\left(\mathrm{Ca}=0,3 \mathrm{cmolc} \mathrm{kg}^{-1}\right.$ e Na= 3,9 $\mathrm{mg} \mathrm{kg}^{-1}$ ). Segundo Askew et al. (1970), estes valores caracterizam solo distrófico. O valor de matéria orgânica no cerradão $\left(81,4 \mathrm{~g} \mathrm{~kg}^{-1}\right)$ é superior ao do cerrado $\left(52,6 \mathrm{~g} \mathrm{~kg}^{-1}\right)$ e considerado alto quando comparado a outros cerradões distróficos e ao bioma como um todo $\left(7-60 \mathrm{~g} \mathrm{~kg}^{-1}\right)$ (Furley \& Ratter, 1988). A textura do solo é argilosa e o $\mathrm{pH}$ praticamente igual (5,0 no cerradão e 4,9 no cerrado denso). Em muitas situações, o cerrado e o cerradão distróficos ocorrem lado a lado (Haridasan, 1992). Nesses casos, a ocorrência do cerradão tem sido frequentemente atribuída à presença de solo mais fértil. Contudo, vários trabalhos têm demonstrado que ambas as fitofisionomias podem ocorrer em solos distróficos de características nutricionais similares (Haridasan, 1992).

Em estudo fitossociológico da comunidade realizado em 2009 (Silva, 2009) seguindo a metodologia proposta por Felfili et al. (2005), foram encontradas 107 espécies pertencentes a 74 gêneros e 40 famílias botânicas, com valores de riqueza, densidade, diversidade (H') e área basal similares aos encontrados em outros cerradões distróficos (Tabela 1). 
Tabela 1. Características florísticas e estruturais de cerradões distróficos. Todos os estudos utilizaram o método de parcelas aleatórias com limite mínimo de inclusão de $5 \mathrm{~cm}$, a $30 \mathrm{~cm}$ do solo $\left(\mathrm{Db}_{30}\right)$.

\begin{tabular}{|c|c|c|c|c|c|c|c|}
\hline Local do estudo & $\begin{array}{c}\text { Área total } \\
\text { amostrada (ha) }\end{array}$ & Hábito & $\begin{array}{l}\mathbf{N}^{\circ} \text { de } \\
\text { espécies }\end{array}$ & $\begin{array}{c}\mathbf{H}^{\prime} \\
\left.\text { (nats ind } .^{-1}\right)\end{array}$ & $\begin{array}{c}\text { Densidade } \\
\text { (ind.ha }^{-1} \text { ) }\end{array}$ & $\begin{array}{c}\text { Área basal } \\
\left(\mathbf{m}^{2} \mathbf{h a}^{-1}\right)\end{array}$ & Fonte \\
\hline REBIO Mário Viana, MT & 0,5 & Arbóreo & 77 & 3,67 & 1.884 & 21,37 & $\begin{array}{c}\text { Marimon Junior \& } \\
\text { Haridasan (2005) }\end{array}$ \\
\hline $\begin{array}{c}\text { APA Gama e Cabeça de } \\
\text { Veado, DF }\end{array}$ & 0,4 & $\begin{array}{l}\text { Arbóreo } \\
\text { (Lenhosas) }\end{array}$ & 51 & 3,17 & 960 & 24 & Felfili et al. (1994) \\
\hline CPAC - Embrapa, DF & 0,4 & $\begin{array}{l}\text { Arbóreo } \\
\text { (Lenhosas) }\end{array}$ & 55 & 3,08 & 1.263 & 23,38 & Felfili et al. (1994) \\
\hline Silvânia, GO & 0,4 & $\begin{array}{l}\text { Arbóreo } \\
\text { (Lenhosas) }\end{array}$ & 89 & 3,56 & 2.082 & 21,64 & Felfili et al. (1994) \\
\hline Patrocínio, MG & 0,4 & $\begin{array}{l}\text { Arbóreo } \\
\text { (Lenhosas) }\end{array}$ & 65 & 3,65 & 1.407 & 17,47 & Felfili et al. (1994) \\
\hline Paracatu, MG & 0,4 & $\begin{array}{c}\text { Arbóreo } \\
\text { (Lenhosas) }\end{array}$ & 81 & 3,21 & 1.382 & 18,03 & Felfili et al. (1994) \\
\hline Curvelo, MG & 1,0 & $\begin{array}{l}\text { Arbóreo } \\
\text { (Lenhosas) }\end{array}$ & 98 & 3,55 & 2.427 & 24,3 & Otoni et al. (2009) \\
\hline $\begin{array}{c}\text { REBIO do Cerradão, } \\
\text { DF }\end{array}$ & 1,0 & $\begin{array}{c}\text { Arbóreo } \\
\text { (Lenhosas) }\end{array}$ & 107 & 3,85 & $1.583 *$ & 20,03 & Silva (2009) \\
\hline
\end{tabular}

Em negrito está representada a área avaliada neste estudo. *Indivíduos mortos em pé não foram considerados.

O elevado valor de diversidade e número de espécies deste cerradão, em relação a outros estudos, adquire maior importância quando se assume que nestas análises não estão incluídos os indivíduos mortos em pé. Sendo assim, é possível afirmar que os valores de densidade e área basal seriam maiores se estes indivíduos fossem considerados.

De acordo com Souza et al. (2010), a riqueza da flora do cerradão deve-se, em parte, à presença de espécies de outros tipos de vegetação, denominadas espécies acessórias. Os autores afirmam que se a classificação em espécies acessórias e peculiares for considerada, pode-se concluir que, independentemente da sua origem florística, tanto o Cerrado, quanto os outros biomas trocaram espécies ao longo do processo de adaptação da flora. Na REBIO, exemplos de espécies acessórias são Heteropterys byrsonimifolia A. Juss., comum em cerrado sensu stricto e Endlicheria paniculata (Spreng.) J.F. Macbr., praticamente restrita a matas ciliares e de galeria (Silva, 2009).

Em relação aos valores de importância (VI) obtidos no estudo fitossociológico da comunidade, realizado por Silva (2009), apenas sete espécies apresentaram
VI maior que 10 e, todas (Emmotum nitens (Benth.) Miers, Qualea grandiflora Mart., Ocotea pomaderroides (Meisn.) Mez, Simarouba versicolor A.St.-Hil., Miconia burchellii Triana, Blepharocalyx salicifolius (Kunth) O.Berg e Terminalia fagifolia Mart.), são comuns às áreas de cerrado sensu stricto e matas de galeria (Silva Junior, 2005; Silva Junior \& Pereira, 2009). Segundo Souza et al. (2010), as espécies de formações florestais encontradas no cerradão parecem ocorrer em seu limite de distribuição, o que o caracteriza como uma vegetação de transição entre a savana e a floresta.

A análise das distribuições de diâmetro foi feita para todos os indivíduos vivos (1.458 ind.ha $\left.^{-1}\right)$ presentes no cerradão estudado e para cada uma das sete espécies mais importantes, citadas acima. A definição do número de classes para cada gráfico foi efetuada a partir do procedimento proposto por Spiegel (Felfili \& Rezende, 2003) e a relação da distribuição dos indivíduos por classes de diâmetro foi avaliada através das análises de regressão e de variância (Tabela 2). Por fim, foi calculado o coeficiente "q" de Liocourt para analisar a relação entre crescimento e mortalidade dos indivíduos por meio de classes diamétricas. 
Tabela 2. Valores da análise de variância (ANOVA) da comunidade como um todo e das principais populações do cerradão inserido na REBIO do Cerradão, DF.

\begin{tabular}{lcc}
\hline \multirow{2}{*}{ Espécies } & \multicolumn{2}{c}{ Análise de Variância (ANOVA) } \\
\cline { 2 - 3 } & F & P \\
\hline Comunidade & 15,35 & 0,002 \\
E. nitens & 37,91 & 0,001 \\
M. burchellii & 12,89 & 0,018 \\
O. pomaderroides & 7,92 & 0,041 \\
B. salicifolius & 3,94 & 0,145 \\
Q. grandiflora & 298,99 & 0,000 \\
S. versicolor & 7,93 & 0,028 \\
T. fagifolia & 3,60 & 0,160 \\
\hline
\end{tabular}

Aproximadamente $62 \%$ dos indivíduos presentes no cerradão apresentaram diâmetros de até $10 \mathrm{~cm}$. Um número elevado de indivíduos com baixos valores de diâmetro é caracterizado pela curva de distribuição diamétrica do tipo J-invertido (Figura 1a) e indica balanço positivo entre recrutamento e mortalidade, sugerindo que a área estudada é auto-regenerativa, recompondose naturalmente na ausência de degradações antrópicas ou naturais (Felfili, 1997). Este tipo de distribuição é característico do bioma Cerrado que apresenta, em toda a sua extensão, maioria de árvores que atingem apenas pequeno porte (Felfili, 2001a). Em áreas de cerrado sensu stricto, poucos indivíduos de algumas espécies exibem porte maior, como Eriotheca pubescens (Mart. \& Zucc.) Schott. (até $85 \mathrm{~cm}$ de diâmetro) e Pterodon emarginatus Vog. (até $70 \mathrm{~cm}$ de diâmetro), aspecto que deve ser considerado nas decisões quanto ao manejo dessas áreas, visto que tornam-se espécies importantes para a manutenção da estrutura da fitofisionomia (Felfili, 2001a; Silva Junior, 2005). No entanto, é necessário considerar a variação que existe no tamanho dos indivíduos, que pode aumentar rapidamente à medida que estes crescem (Hutchings, 1997). De acordo com Hutchings (1997), esta variação pode ainda ser influenciada pela competição e pela heterogeneidade do habitat.

Dentre as espécies mais importantes deste cerradão, apenas $T$. fagifolia não apresentou distribuição diamétrica do tipo J-invertido, com o menor valor do coeficiente de determinação $\left(\mathrm{R}^{2}\right)$ e o coeficiente " $\mathrm{q}$ " de Liocourt altamente variável (Figura 1b). O maior número de indivíduos da espécie nas classes diamétricas intermediárias pode ser reflexo da característica de suas sementes, que sofrem dormência, como sugerido por Netto \& Faiad (1995).

E. nitens e $S$. versicolor foram as únicas que obtiveram falha em uma das últimas classes de diâmetro, o que pode significar problema no ciclo de vida destas espécies, devido a interferências antrópicas ou naturais, ou simplesmente a ausência da amostragem nesse intervalo de diâmetro.

Segundo Ramos (1990), E. nitens (Figura 1c) não é adaptada a ocorrências frequentes de incêndio por não possuir sistema radicular espessado e com reservas nutricionais, como ocorre com algumas espécies do cerrado sensu stricto, sendo por isso mais susceptível ao fogo. Por outro lado, apresenta bom crescimento, sendo inclusive bastante utilizada para a recuperação de áreas degradadas (Corrêa, 2005).

S. versicolor (Figura 1d) apresentou $68 \%$ dos indivíduos na primeira classe de diâmetro (até $8,5 \mathrm{~cm}$ ) e diâmetro máximo observado igual a $30 \mathrm{~cm}$, valor inferior aos encontrados na literatura. Silva Júnior (2005) afirma que esta espécie pode apresentar diâmetros de até $60 \mathrm{~cm}$. S. versicolor, assim como E. nitens, é uma espécie pioneira intolerante à sombra (Lorenzi, 1998) e, segundo Felfili (1997), estas espécies tendem a crescer rapidamente para atingir plena luz no dossel e apresentam como característica da curva de distribuição a escassez ou a ausência de indivíduos em classes diamétricas intermediárias. A ausência da amostragem de indivíduos de $S$. versicolor na penúltima classe diamétrica pode ser resultado da ampla dispersão da espécie que é feita por pássaros e morcegos (Silva Junior, 2005).

Quanto à presença de fogo, segundo Hoffmann et al. (2009), se as queimadas forem frequentes, indivíduos arbóreos de menor porte podem não sobreviver ou serem incapazes de crescer e atingir classes de tamanho maiores e, até mesmo indivíduos grandes, podem perder sua copa ou biomassa aérea ("topkill") e retrocederem para classes de tamanho menores de forma irreversível.

Evento semelhante pode ter ocorrido com os indivíduos de O. pomaderroides (Figura 1e), espécie comum de ambientes florestais no bioma Cerrado, que apresentou distribuições irregulares entre as classes de diâmetro e alta queda da primeira para as demais classes. De acordo com Higgins et al. (2000), após a passagem do fogo, a eliminação da parte aérea das árvores e a taxa de rebrota podem controlar mudanças na estrutura de muitas savanas tropicais. Souza \& Soares (1983) em um cerradão protegido do fogo por 50 anos, constataram que, seis meses após uma queimada, $77 \%$ das espécies tiveram brotamento da parte basal e apenas 3\% na parte epígea. 


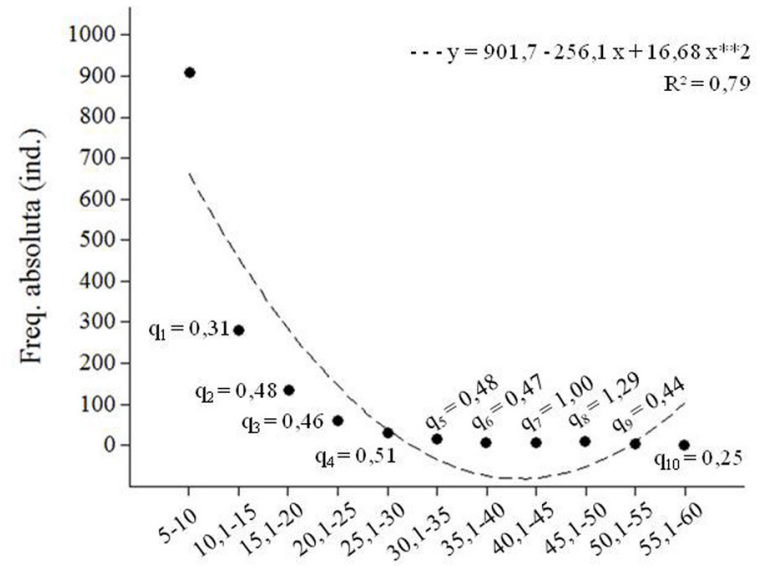

Classes de diâmetros $(\mathrm{cm})$
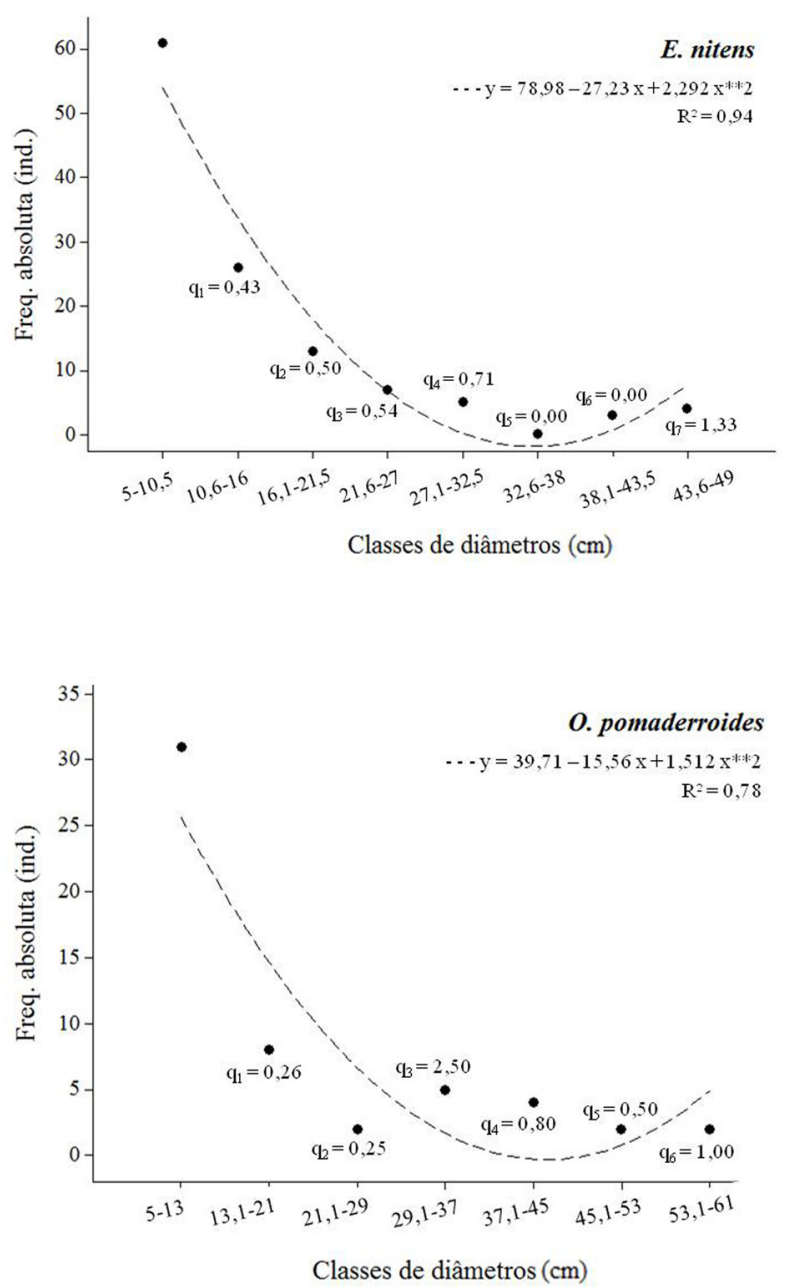
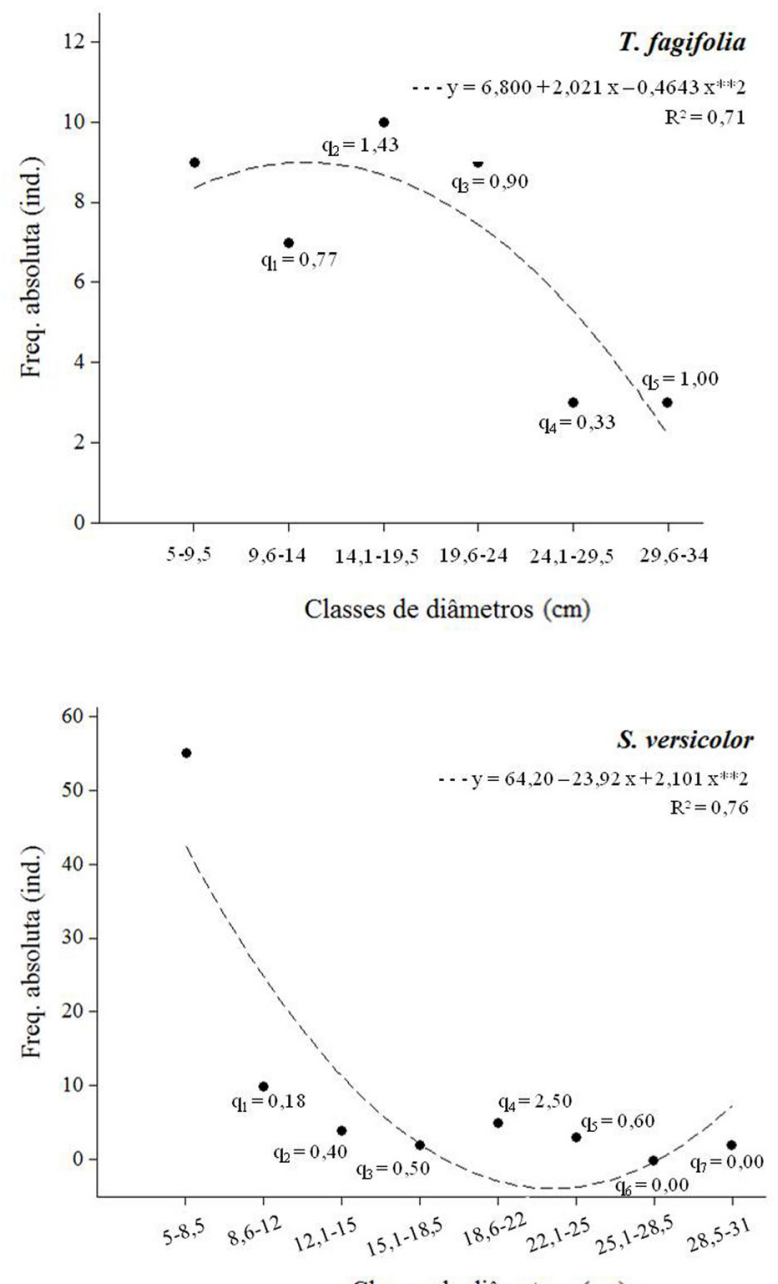

Classes de diâmetros $(\mathrm{cm})$

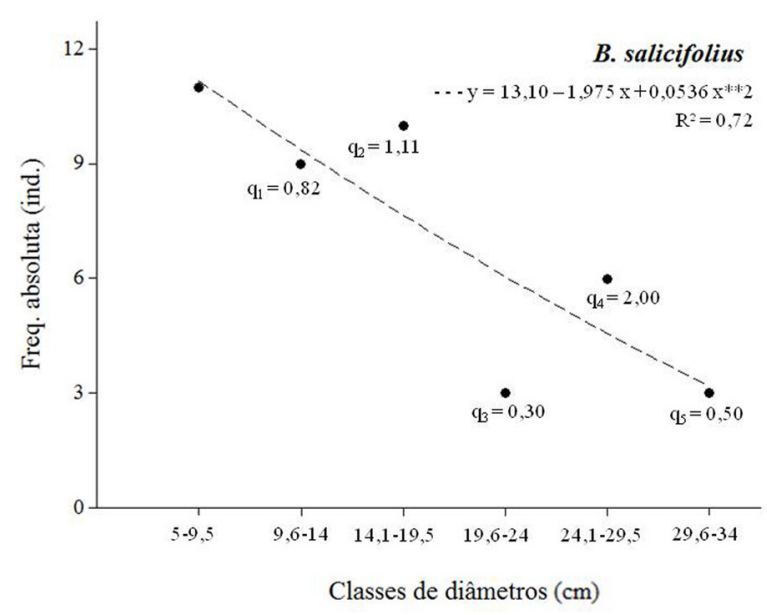

Figura 1. Distribuição de frequência dos indivíduos nas classes diamétricas, coeficiente de Liocourt (q) e coeficiente de determinação $\left(\mathrm{R}^{2}\right)$ para a comunidade inteira e as sete principais populações da REBIO do Cerradão, DF. Os pontos representam as frequências observadas e a linha tracejada, o ajuste à curva "J-invertido" $(\mathrm{Yi}=\beta 0+\beta 1 \mathrm{Xi}+$ ei $)$. 


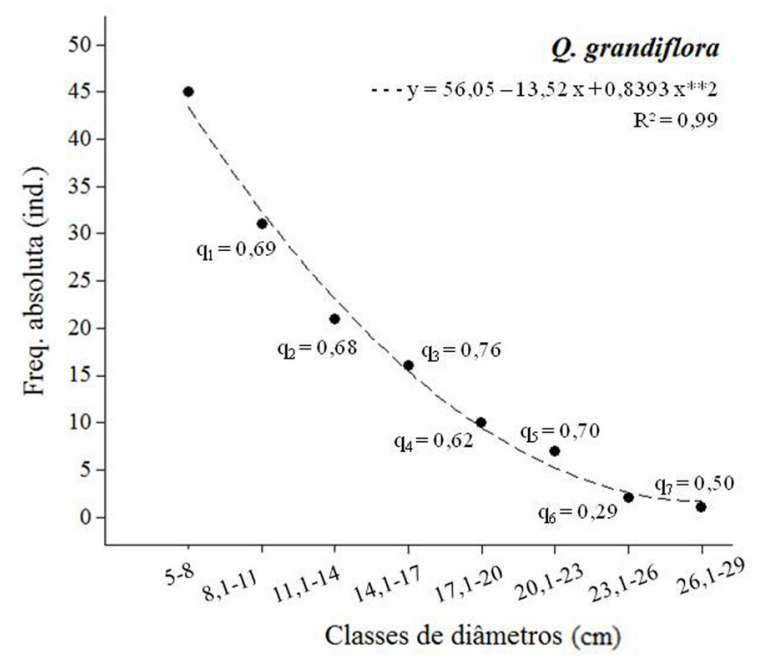

Figura 1. Continuação.

Não há registros formais de incêndios ocorridos na REBIO, no entanto, segundo Gilvanir Assunção, vigilante da Escola de Administração Fazendária, vizinha à REBIO do Cerradão, em meados de 20062007 houve uma queimada de grandes proporções que atingiu todo o território da $\mathrm{UC}$ e foi contida pelo Corpo de Bombeiros.

A passagem do fogo na área tende a aumentar a importância da reprodução vegetativa em relação à reprodução sexuada (Hoffmann, 1998). Indivíduos de maior porte podem perder somente as folhas e ramos finos devido ao alto aquecimento provocado pelas chamas, podendo rebrotar a partir das gemas dormentes da copa, enquanto indivíduos menores podem sofrer com a morte da sua copa ou biomassa aérea, apresentando rebrotamento a partir de gemas no nível do solo ou de outras estruturas subterrâneas (Miranda et al., 2002).

B. salicifolius (Figura 1f) apresentou mais de 70\% dos indivíduos nas três primeiras classes de diâmetro (até $19,5 \mathrm{~cm}$ ) e oscilações nas classes posteriores. A alta variação nos valores do coeficiente "q" de Liocourt e o baixo valor de $\mathrm{R}^{2}$ evidenciam a estrutura irregular pouco ajustada à curva J-invertido, e distribuições não balanceadas. De acordo com Matos (1994), a ação do fogo dificulta o crescimento das plântulas dessa espécie, porém indivíduos estabelecidos sobrevivem e rebrotam após a ocorrência do fogo. Rego et al. (2009) mostraram que a espécie, frequente em locais

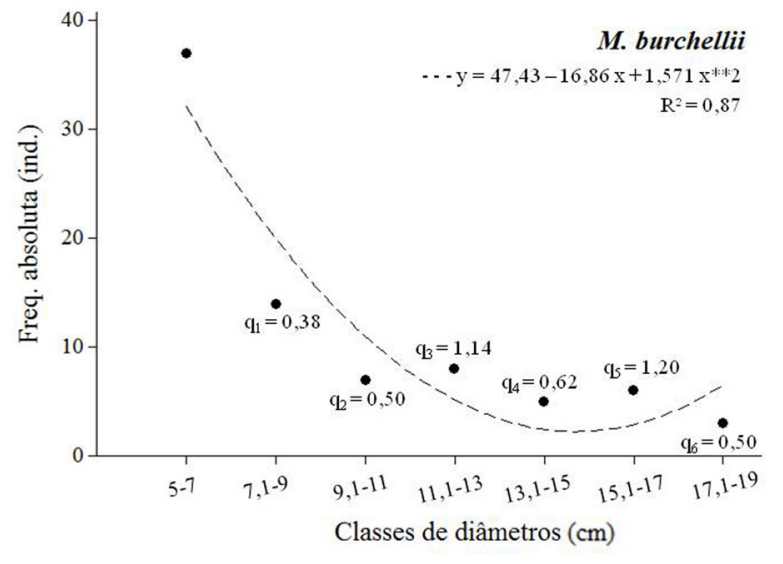

úmidos, apresenta germinação mais bem sucedida em substratos de muito úmidos a encharcados, independente da incidência de luz.

Q. grandiflora (Figura 1g), M. burchellii (Figura 1h) e E. nitens foram as espécies com distribuição diamétrica mais balanceada e com maior tendência ao equilíbrio, conforme valores de "q" e " $\mathrm{R}$ "), indicando que tais espécies possuem um bom equilíbrio entre mortalidade e crescimento, apesar da última ter apresentado falha em uma das classes de maiores diâmetros.

Segundo Bernasol \& Lima-Ribeiro (2010), espécies que possuem equilíbrio entre mortalidade e crescimento são menos influenciadas pelas perturbações ambientais, principalmente às de origem antrópica.

Tendo em vista que a análise das medidas diamétricas das espécies vegetais mais importantes de uma área é uma ferramenta útil para diagnosticar estrutura, potencial regenerativo e manutenção da vegetação, pode-se concluir que a comunidade estudada parece ter potencial regenerativo, seja por meio de rebrota ou germinação de sementes, pois apresenta a maior parte dos indivíduos com baixos valores de diâmetros, situação comum nas fitofisionomias do Cerrado em anos subsequentes a incêndios. Além disso, todas as espécies presentes na REBIO são compartilhadas com fitofisionomias savânicas e/ou florestais do bioma (Silva, 2009), confirmando a "flora mista" típica dos 
cerradões e contribuindo para a importância deste fragmento em termos de conservação. Da mesma forma, as características edáficas da REBIO, parecem reforçar a hipótese de Haridasan (1992) que tanto a fertilidade do solo, quanto a disponibilidade de $\mathrm{Ca}, \mathrm{Mg}$ e K não são as principais responsáveis pela transição cerrado - cerradão.

Contudo, para que afirmações mais contundentes possam ser feitas a respeito da dinâmica e do potencial regenerativo da área, sugere-se que novas medições de diâmetro das populações aqui estudadas sejam realizadas.

\section{Referências}

ARAÚJO, G. M.; HARIDASAN, M. A comparison of the nutrients status of two forests on dystrophic and mesotrophic soils in the cerrado region of central Brazil. Communications in Soil Science and Plant Analysis, New York, n. 19, p. 1075-1089, 1988.

ASKEW, G. P.; MOFFATT, D. J.; MONTOGOMERY, R. F.; SEARL, P. L. Soil landscapes in north eastern Mato Grosso. The Geographical Journal, Hoboken, v. 136, n. 2, p. 211-227, 1970.

BERNASOL, W. P.; LIMA-RIBEIRO, M. S. Estrutura espacial e diamétrica de espécies arbóreas e seus condicionantes em um fragmento de cerrado sentido restrito no sudoeste goiano. Hoehnea, São Paulo, v. 37, n. 2, p. 181-198, 2010.

CORREAA, R. S. Recuperação de áreas degradadas: manual para revegetação. Brasília, DF: Universa, 2005. 187 p.

DISTRITO FEDERAL (Brasil). Decreto n. 31.757, de 2 de junho de 2010. Transforma a Área de Relevante Interesse Ecológico ARIE do Cerradão, localizado na Região Administrativa do Jardim Botânico -RA XXVII, em Reserva Biológica do Cerradão, nos termos do artigo 10, da Lei Federal $n^{\circ}$ 9.985, de 18 de julho de 2000, e dá outras providências. Diário Oficial do Distrito Federal (DODF), seção 1, p. 20, 7 jun. 2010.

DISTRITO FEDERAL (Brasil). Secretaria do Meio Ambiente e dos Recursos Hídricos. Mapa ambiental do Distrito Federal. Brasília, DF: GDF. 2006.

FELFILI, J. M.; CARVALHO, F. A.; HAIDAR, R. F. Manual para o monitoramento de parcelas permanentes nos Biomas Cerrado e Pantanal. Brasília, DF: Ed da UnB, 2005. 55 p.

FELFILI, J. M. Diameter and height distributions of a gallery forest community and some of its mains species in Central Brazil over a six-year period (1985-1991). Revista Brasileira de Botânica, São Paulo, n. 20, p. 155-162, 1997.

FELFILI, J. M. Distribuição de diâmetros de quatro áreas de cerrado sensu stricto na Chapada do Espigão Mestre do São Francisco. In: FELFILI, J. M.; SILVA JÚNIOR, M. C. (Org.). Biogeografia do Bioma Cerrado: estudo fitofisionômico na Chapada do Espigão Mestre do São Francisco. Brasília, DF: Ed da UnB, 2001a. p. 57-60.
FELFILI, J. M.; FILGUEIRAS, T. S.; HARIDASAN, M.; SILVA JÚNIOR, M. C.; MENDONÇA, R.; REZENDE, A. V. Projeto Biogeografia do Bioma Cerrado: vegetação e solos. Caderno de Geociências do IBGE, Rio de Janeiro, n. 12, p. 75-166, 1994.

FELFILI, J. M. Principais fisionomias do Espigão Mestre do São Francisco. In: FELFILI, J. M.; SILVA JÚNIOR, M. C. (Org.). Biogeografia do Bioma Cerrado: estudo fitofisionômico na Chapada do Espigão Mestre do São Francisco. Brasília, DF: Ed da UnB, 2001b. p. 18-30.

FELFILI, J. M.; REZENDE, R. P. Conceitos e métodos em fitossociologia: comunicações: técnicas florestais. Brasília, DF: Ed da UnB, 2003. 68 p.

FURLEY, P. A.; RATTER, J. A. Soil resources and plant communities of the central Brazilian cerrado and their development. Journal of Biogeography, Hoboken, v. 15, p. 97-108, 1988.

HARIDASAN, M. Observations on soils, foliar nutrient concentrations, and floristic composition of cerrado and cerradão communities in central Brazil. In: PROCTOR, J.; RATTER, J. A.; FURLEY, P. A. (Ed.). The nature and dynamics of forest-savanna boundaries. London: Chapman \& Hall, 1992. p. 171-184.

HIGGINS, S. I.; BOND, W. J.; TROLlOPE, W. S. W. Fire, resprouting and variability: a recipe for grass-tree coexistence in savanna. Journal of Ecology, Hoboken, v. 88, p. 213-29, 2000.

HOFFMANN, W. A. Post-burn reproduction of woody plants in a neotropical savanna: the relative importance of sexual and vegetative reproduction. Journal of Applied Ecology, London, v. 35, p. 422433, 1998.

HOFFMANN, W. A.; ADASME, R.; HARIDASAN, M.; CARVALHO, M. T.; GEIGER, E. L.; PEREIRA, M.A. B.; GOTSCH, S. G.; FRANCO, A. C. Tree topkill, not mortality, governs the dynamics of savana-forest boundaries underfrequent fire in central Brazil. Ecology, New York, v. 90, p. 1326-1337, 2009.

HUTCHINGS, M. J. The structure of plant populations. In: CRAWLEY, M. J. (Ed.). Plant ecology. Oxford: Blackwell Science, 1997. p. 325-358.

IMAÑA-ENCINAS, J.; MACEDO, L. A.; PAULA, J. E. Florística e fitossociologia de um trecho da floresta estacional semidecidual na área do Ecomuseu do Cerrado, em Pirenópolis - Goiás. Cerne, Lavras, v. 13, n. 3, p. 308-320, 2007.

INSTITUTO BRASÍLIA AMBIENTAL. Proposta de mudança de categoria: área de relevante interesse ecológico do Cerradão: Reserva Biológica do Cerradão. Brasília, DF: GDF, 2010.

LORENZI, H. Árvores brasileiras: manual de identificação e cultivo de plantas arbóreas do Brasil. Nova Odessa: Instituto Plantarum, 1998. 2 v. 384 p.

MARIMON JUNIOR, B. H.; HARIDASAN, M. Comparação da vegetação arbórea e características edáficas de um cerradão e um cerrado sensu stricto em áreas adjacentes sobre solo distrófico no leste de Mato Grosso, Brasil. Acta Botanica Brasilica, Porto Alegre, v. 19, n. 4, p. 913-926, 2005. 
MATOS, M. R. B. Efeito do fogo sobre regenerantes de Blepharocalyx salicifolius (H.B.K.) Berg. (Myrtaceae) em cerrado aberto. 1994. 70 f. Dissertação (Mestrado em Ecologia) Universidade de Brasília, Brasília, DF.

MINITAB INC. Minitab® Statistical Software. 2007. Disponível em: <www.minitab.com>. Acesso em 08 ago. 2012.

MIRANDA, H. S.; BUSTAMANTE, M. M. C.; MIRANDA, A. C. The fire factor. In: OLIVEIRA, P. S.; MARQUIS, R. J. (Ed.). Cerrados of Brazil: ecology and natural history of a neotropical savana. New York: Columbia University Press, 2002. p. 51-68.

NETTO, D. A. M.; FAIAD, M. G. R. Viabilidade e sanidade de sementes de espécies florestais. Revista Brasileira de Sementes, Londrina, v. 17, n. 1, p. 75-80, 1995.

OTONI, T. J. O.; MOTA, S. L. L.; PEREIRA, I. M.; OLIVEIRA, M. L. R.; COSTA, L. A. Composição florística, análise fitossociológica e estrutural de uma floresta de cerradão, Curvelo-MG. In: ENCONTRO LATINO AMERICANO DE INICIAÇÃO CIENTÍFICA E IX ENCONTRO LATINO AMERICANO DE PÓS-GRADUAÇÃO, 13, 2009, São José dos Campos. Resumos... São José dos Campos: Universidade do Vale do Paraíba, 2009. p. 1-6.

RAMOS, A. E. Efeitos da queima sobre a vegetação lenhosa do cerrado. 1990. 141 f. Dissertação (Mestrado em Ecologia) Universidade de Brasília, Brasília, DF.

REGO, S. S.; NOGUEIRA, A. C.; KUNIYOSHI, Y. S.; SANTOS, A. F. Germinação de sementes de Blepharocalyx salicifolius (H.B.K.) Berg. em diferentes substratos e condições de temperaturas, luz e umidade. Revista Brasileira de Sementes, Londrina, v. 31, n. 2, p. 212-220, 2009.

RIBEIRO, J. F.; WALTER, B. M. T. As principais fitofisionomias do bioma Cerrado. In: SANO, S. M.; ALMEIDA, S. P.; RIBEIRO, J. F. Cerrado: ecologia e flora. Brasília, DF: Embrapa Informação Tecnológica; Planaltina, DF: Embrapa Cerrados, 2008. p. 151-212.
SANTOS, R. M.; VIEIRA, F. A.; GUSMÃO, E.; NUNES, Y. R. F. Florística e estrutura de uma floresta estacional decidual, no Parque Municipal da Sapucaia, Montes Claros (MG). Cerne, Lavras, v. 13, n. 3, p. 248-256, 2007.

SCOLFORO, J. R. S.; PULTZ, F. A.; MELO, J. M. Modelagem da produção, idade das florestas nativa, distribuição espacial das espécies e a análise estrutural. In: SCOLFORO, J. R. S. (Coord.). Manejo florestal. Lavras: UFLA/FAEPE, 1998. p. 189-246.

SILVA, J. S. Diversidade alfa, florística e fitossociologia na ARIE do Cerradão, na APA Gama e Cabeça de Veado, DF. 2009. 126 f. Dissertação (Mestrado em Botânica) - Universidade de Brasília, Brasília, DF.

SILVA JÚNIOR, M. C. 100 árvores do cerrado: guia de campo. Brasília, DF: Rede de Sementes do Cerrado, 2005. 278 p.

SILVA JÚNIOR, M. C.; PEREIRA, B. A. S. + 100 árvores do cerrado: matas de galeria: guia de campo. Brasília, DF: Rede de Sementes do Cerrado, 2009. 288 p.

SILVA JÚNIOR, M. C.; SILVA, A. F. Distribuição dos diâmetros dos troncos das espécies mais importantes do cerrado na Estação Florestal de Experimentação de Paraopeba (EFLEX)-MG. Acta Botanica Brasilica, Porto Alegre, v. 2, n. 1-2, p. 107-126, 1988.

SOUZA, M. H. A. O.; SOARES, J. J. Brotamento de espécies arbustivas e arbóreas, posteriormente a uma queimada. In: SEMINÁRIOS REGIONAIS EM ECOLOGIA, 3, 1983, São Carlos. Resumos... São Carlos: Universidade Federal de São Carlos, 1983. p. 263-275.

SOUZA, P. B.; SAPORETTI JUNIOR, A. W.; SOARES, M. P.; VIANA, R. H. O.; CAMARGOS, V. L.; MEIRA NETO, J. A. A. Florística de uma área de cerradão na Floresta Nacional de Paraopeba - Minas Gerais. Cerne, Lavras, v. 16, n. 1, p. 86-93, 2010. 